BARRETT, N. P. (1946): Spontaneous Rupture of the Oesophagus-Review of the Literature and Report of 3 cases, Thorax, 48, 1 .

BarreTt, N. P. (1947): Report of a Case of Spontaneous Rupture of the Oesophagus successfully treated by Operation, Brit. J. Surg., 216, 35.

BEAL, J. M. (1949): Spontaneous Rupture of the Oesophagus, Ann. Surg., 129, 572.

Bunch, G. H. (Jr.) (1957): Spontaneous Rupture of the Oesophagus, 2 Cases of Recovery, Ann. Surg., 145, 1001.

Chamberlain, J. M., and Brierley, W. G. (1957): Rupture of the Oesophagus, Amer. J. Surg., 93, 271.

Cushing, H. (1932): Peptic Ulcers and the Interbrain, Surg. Gynec. Obstet., 55, 15.

Derbes, V. J., and Mitchell, R. E. (Jr.) (1956): Rupture of the Oesophagus, Surg., 39, 688, 865.

KENNARD, H. W. (1950): Rupture of the Oesophagus during Childbirth, Brit. med. J., i, 417.

La HochberG, and Palamis, N. (1961): Spontaneous Perforation and Rupture of the Oesophagus with a Report of 5 Cases, Amer. J. Surg., 102, 428.

MACKLER, S. A. (1962): Spontaneous Rupture of the Oesophagus, an Experimental and Clinical Study. Surg. Gynec. Obstet., 95, 345.
McPhedran, N. T. (1961): Spontaneous Rupture of the Oesophagus, Canad. J. Surg., 4, 443.

MAHON, R. D., and RoBINSON, L. (1960): Spontaneous Rupture of the Oesophagus, Amer, Surg., 26, 24.

Mallam, P. C., Whitelock, H. A. B., and RobB SMITH, A. M. (1940): Spontaneous Rupture of the Oesophagus, Brit. J. Surg., 27, 795.

MARSTON, E. L., and VALK, H. (1959): Spontaneous Perforation of the Oesophagus-Review of the Literature and Report of a Case, Ann. intern. Med., 51, 590.

Mitchell, R. E., Derbes, V. J., and Aitkenhead, W. R. (1935): Rupture of the Oesophagus, 2 Instances of a Hitherto Undescribed Complication of Status Asthmaticus, Ann. Allergy (1935) but reference quoted from Allergy, 26, Abstracts 51 .

NACHERIO, E. A. (1957): The V sign in the Diagnosis of Spontaneous Rupture of the Oesophagus (an early Roentgen clue), Amer. J. Surg., 93, 291.

PARRISH, C. M. (1961): Spontaneous Rupture of the Oesophagus and Report of 2 Cases, Amer. Surg., 27, 553.

Ross, J. G. (1961): Spontaneous Rupture of the Middle Third of the Oesophagus, Brit. J. Surg., 48, 633 .

\title{
A CASE OF NON-FAMILIAL DEGENERATIVE CHOREA
}

\author{
Fathy W. Tadros, Ph.D., M.R.C.P., D.P.M. \\ Ellen Nicola, M.D. (Path), D.M.Sc. \\ ISMAIL AMIN, M.S., D.P.M. \\ From the Faculty of Medicine, Cairo University.
}

Degenerative changes in the central grey matter of the brain as well as in the cortex give a wide range of the so-called extra-pyramidal syndromes which affect mainly the posture and sometimes the motion of the afflicted persons. Different forms of involuntary movements, namely, static tremor, chorea, choric-athetosis, dystonic and intentional tremors are described. Groups of these are often classified into clear-cut clinical syndromes and further attempts at their classification into clinicopathological syndromes have often been attempted. Examples are paralysis agitans, Huntington's chorea and olive-ponto-cerebellar degeneration. Yet in analysing the reports of such syndromes, it is noted that the pathological pictures are not often indentical as regards the site or nature in all members of one group. If we consider the syndrome of Huntington's chorea, it is noted that the different reported cases show protean pathological changes and a variety of sites for the degenerative changes. They are reported in the lentiform nucleus or only the putamen (Lannois and Paviot, 1898, Alzheimer, 1914, Bielschowsky, 1922, Dunlop, 1927). In some cases lesions appear in the putamen and caudate nucleus (Marie and Lhermitte, 1914; Kleist, 1912; Vogt, 1920; Hunt, 1916; V. Santha, 1931; Jacob, 1923). The cortex is reported to be affected in several cases (Pfeiffer, 1913; V. Santha, 1931; Lind, 1927).
The changes usually occur in the 3rd, 5th and 6th cortical layers (Pfeiffer, 1913; Santha, 1931). In quite a number of cases the meninges are also affected, showing chronic inflammation and/or thickening of the arachnoid (Grimbly and Wilson, 1926; Frederick Back, 1926; Marie and Lhermitte, 1914). Clinically these cases are typified as presenting gradual and progressive choreic movements starting usually in middle age. The movements are coarse and involve the face and tongue. The disease terminates with progressive mental deterioration. It is often stressed that the disease is hereditary and transmitted as a Mendelian dominant.

It is therefore of interest to report this case of degenerative chorea which shows atypical chronological and pathological pictures.

\section{Case Report}

A. M., male of 40 years admitted to hospital on 21.11.61. The condition started with choreic movements in right upper limb followed one month later by movements in the left lower limb which then became generalised. It was of three years duration and of progressive course. No family history of similar disease could be obtained from the patient, and mental changes were absent. The patient related the onset of the disease to an attack of fever of undetermined nature. On examination, there were generalised choreiform movements, tremors of the tongue and slight generalised hyper-reflexia.

政

政

(2)




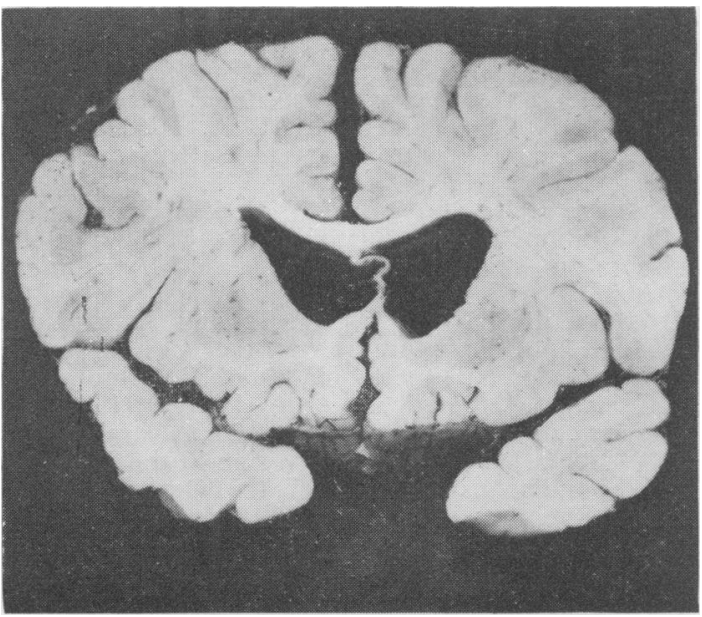

FIG. 1.-Coronal section of the brain showing marked atrophy of both caudate nuclei in contrast to the lentiform nuclei. There is atrophy of central white matter, widening of gyri and dilatation of lateral ventricles.

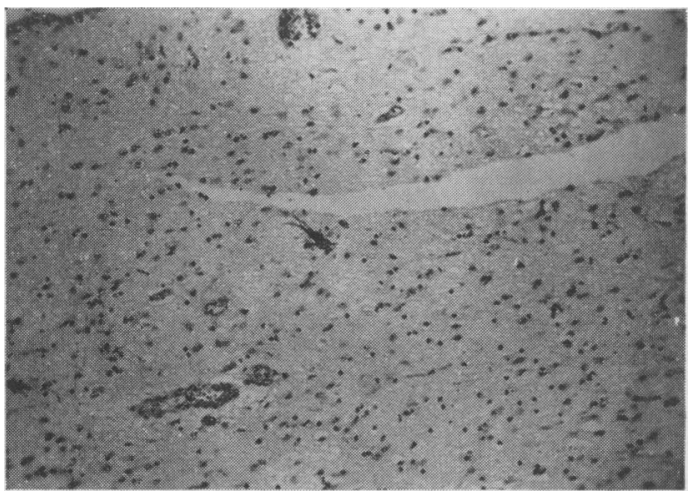

FIG. 3.-Microphotograph of caudate nucleus showing absence of nerve cells and proliferation of glial cells and fibres (Nissl stain) ( $X 100)$.

The case was clinically diagnosed as Huntington's chorea and subjected to left pallidotomy on 19.12.61. After operation all choreiform movements ceased; rigidity in both upper limbs, particularly the right, was present. Confusion, aphasia and gradual deterioration ended in coma and death on the 8th post-operative day.

\section{Autopsy}

The arachnoid showed no abnormality. The cerebrum was generally smaller than normal with wide sulci. Compensatory dilatation of the ventricular system was present. Both caudate nuclei were atrophic with consequent widening of the area of the internal capsule (Figs. 1 and 2). The widening involved the internal capsule as well as the areas of gliosis replacing the atrophic parts of the caudate nuclei. The lentiform nuclei and thalami were normal. The cerebral cortex of the frontal and temporal lobes was relatively thinner compared to that of parietal and occipital lobes. The operation wound

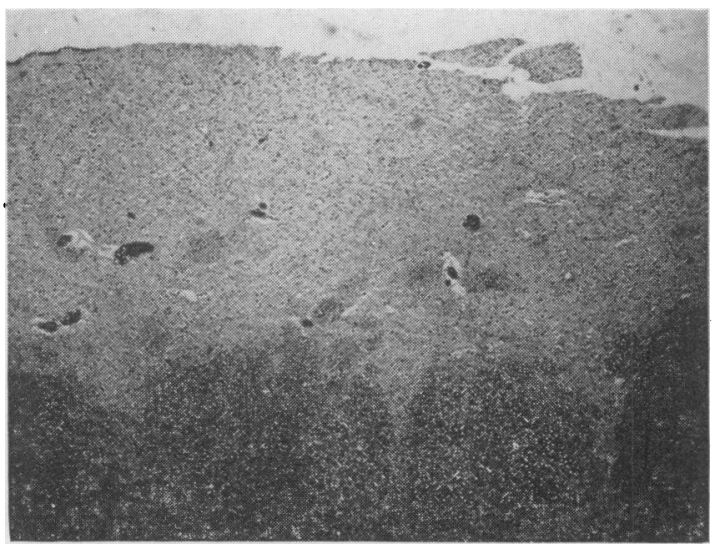

FIG. 2.-Microphotograph of head of caudate nucleus showing marked diminution in size in contrast to the adjacent internal capsule (Loyez stain) (X 7).

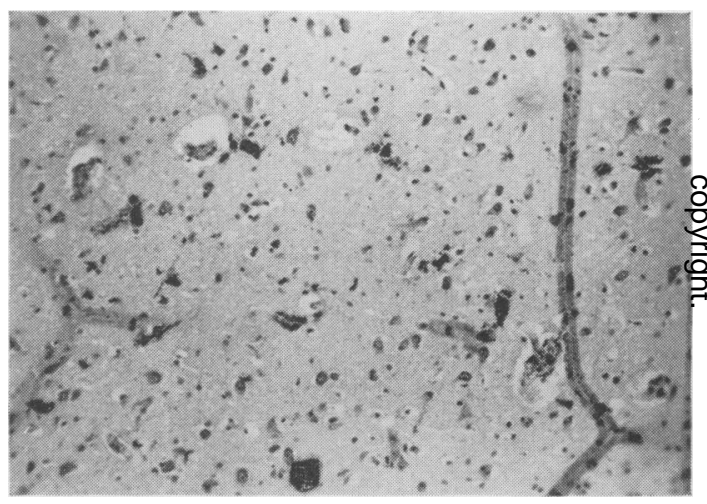

FIG. 4.-Microphotograph of putamen showing normal cellular population. No evidence of degeneration (Nissl stain) $(X 100)$.

at the site of the thalamus did not show any extensive hæmorrhage.

Microscopically, the caudate nucleus showed diminution in number of both the small and large cells. Some of the remaining cells showed chromatolysis by the toluidine blue stain (Fig. 3). There was no increase in the number of glial cells despite the presence of dense glial fibres. The lentiform nucleus and thalamus were normal (Fig. 4). In the cortex there was diminition of nerve cells in the of first three cortical layers with proliferation of glial fibres. (The fifth and sixth layers showed no diminution of the cellular population).

The rest of the body showed no contributory pathologic changes. There was left lower lobar pneumenia and bilharziasis of large intestines, urinary bladder and seminal vesicles.

\section{Discussion}

The case presented differs from the classical Huntington's chorea in several respects. Firstly, 
the absence of mental changes and family history. Secondly, the meningeal reaction was not present. Thirdly, the lesion in the corpus stiatum was strictly confined to the caudate nuclei with normal lentiform nuclei. The thalamus showed no pathological abnormality. Fourthly, it is stated by various authors that the lesion in the corpus striatum affects principally the small ganglion cells with sparing of, or slight affection of, the large one (Jacob, 1923). In our case both types of cells were damaged and atrophied. Lastly in contradistinction to previously reported cases in which the main brunt falls on the fourth, fifth and sixth layers of the cerebral cortex with sparing of the first three layers, in our case just the reverse has occurred.

\section{REFERENCES}

Alzheimer, A. (1911): Neurol. Zbl., 30, 891. Quoted in Neurology by S. A. Kinnier Wilson, Vol. 2, 989. London: Butterworth (1954).

BACK, F. (1926): Huntington's Chorea, Brit. med. J., ii, 60 .

BielsChOWSKy, M. (1922): J. Psychol. Neurol. (Lpz.), 27, 333. Quoted by ibid. Vol. 2, 989.
DunloP, C. B. (1927): Pathologic Changes in Huntington's Chorea with special reference to Corp. Striatum. Arch. Neurol. Psychiat., 18, 867.

Grimbly, A. F., and Wilson, I. G. H. (1926): A Commentary on Two Cases of Huntington's Chorea, Brit. med. J., 1, 820 .

HuNT, J. R. (1916): J. nerv. ment. Dis., 44, 437. Quoted in Neurology by S. A. Kinnier WilsonVol. 2, 989. London: Butterworth (1954).

JACOB, A. (1923): Die Extrapyramidakn, 717, 935, 973, 978, 989, 1044. Berlin: Springer.

KLEIST, K. (1912): Neurol. Zbl., 31, 1460. Quoted in Neurology by S. A. Kinnier Wilson-Vol. 2, 989. London: Butterworth (1954).

Lannois, M., and Paviot, S. (1898): Rev. Méd. (Paris), 18, 207. Quoted by ibid, Vol. 2, 989.

LiND, W. A. T. (1927): Mental Symptoms and Postmortem Appearances in Huntington's Chorea. Med. J. Aust., 2, 23.

Marie, P., and Lhermitte, J. (1914): Ann. Med., 1, 18, 989. Quoted in Neurology by S. A. Kinnier Wilson, Vol. 2, 989. London: Butterworth (1954).

Pfeiffer, J. A. F. (1913): Brain, 35, 276. Quoted by ibid, Vol. 2, 988.

Vogt, C., and Vogt. O. (1920): J. Psychiat. Neurol., 25, 1. Quoted by ibid, Vol. 989.

Von SANTHa, K. (1931): Zur Pathologie Derbereditaren Chorea, Arch. Psychiat., 95, 455.

\title{
A BILATERAL AND FUNCTIONING BRENNER TUMOUR OF THE OVARY
}

\author{
Salvino Muscat, M.D., M.R.C.O.G., \\ Lately, Demonstrator in Obstetrics and Gynacology, \\ Royal University of Malta.
}

BRENNER tumours of the ovary are encountered only rarely. Mackinlay (1956) considers that few authors deal with more than four or five cases in their lifetime. This particular case was associated with uterine hæmorrhage many years after the menopause. The other interesting feature was that the Brenner tumour was bilateral. Farrar and Greene (1960) surveyed the literature and found only 27 reported cases of bilateral Brenner tumours of the ovary and to these they added two of their own.

\section{Case Report}

Mrs. T. B., aged 67 years, was originally seen on 3rd August, 1963. The marriage had been childless and there were no miscarriages. The menopause occurred at the age of 44 ; this was completely uneventful until the beginning of June, 1963, when she started losing blood p.v. The bleeding was intermittent in nature with periods of complete freedom varying from seven to ten days. The blood loss was described as slight to moderate "much like a period" and was associated with slight lower abdominal pain, hot flushes and heaviness in the breasts.

Her general condition was good. Routine abdominal and bimanual examination was inconclusive as the patient's abdomen was pendulous and very obese.

An examination under anaesthesia, followed by a diagnostic curettage, were performed on the 9th August, 1963. The vulva, vagina and cervix were normal. The uterus was anteverted, mobile and definitely bulky, but had a smooth surface and a firm consistency. The left ovary was hard, mobile and approximately the size of a pigeon's egg. The right ovary was definitely palpable and was judged to be slightly enlarged though not to the same extent as that on the left side. The uterine sound was introduced to a length of $4 \frac{1}{2}$ inches. On curettage profuse bulky curettings were recovered.

Two days later a total hysterectomy and a bilateral salpingo-ocphorectomy were carried out. At operation the findings of the previous examination 